\title{
ENTREVISTA COM WALTER CARLOS COSTA
}

\section{INTERVIEW WITH WALTER CARLOS COSTA}

\author{
Andréia Guerini \\ Universidade Federal de Santa Catarina \\ $\mathrm{CNPq} / \mathrm{Capes}$ \\ Florianópolis, Santa Catarina, Brasil
}

Robert de Brose

Universidade Federal do Ceará

Fortaleza, Ceará, Brasil

WALTER CARLOS COSTA, professor, tradutor e pesquisador do CNPq Nível 2, é uma figura central nos Estudos da Tradução no Brasil, seja pela sua longa e prolífera carreira como pesquisador nesta área, que ajudou a consolidar no país, seja pela sua atuação na formação de novos tradutores, pesquisadores e professores. Sua carreira iniciou-se com a graduação em Filologia Românica (Francês e Espanhol) na Katholieke Universiteit Leuven, Bélgica, onde também escreveu sua dissertação de mestrado sobre questões relacionadas à tradução do Grande Sertão: Veredas de João Guimarães Rosa para o francês, trabalho desenvolvido sob a orientação do eminente pesquisador, bem como um dos fundadores dos Estudos da Tradução, José Lambert. Entre 1988 e 1992, escreveu sua tese de doutoramento sobre os aspectos linguísticos da tradução de Jorge Luís Borges na Universidade de Birminghan, sob a orientação de Malcolm Coulthard. É Professor aposentado pela Universidade Federal de Santa Catarina, onde continua atuando na Pós-Graduação em Estudos da Tradução (PGET) daquela instituição, e Professor Visitante junto ao Programa de Pós-graduação em Estudos da Tradução da Universidade Federal do Ceará (POET - UFC), do qual é um dos fundadores, desde 2017. Atualmente, dedica-se, principalmente, à pesquisa da literatura de Jorge Luis Borges e Adolfo Bioy Casares e à história e historiografia da tradução. 


\section{ENTREVISTA COM WALTER CARLOS COSTA}

\section{Revista da Anpoll (RA): Comente sobre o seu contato inicial com a tradução.}

Walter Carlos Costa (WCC): Meu contato inicial com a tradução data da infância, passada na pequena cidade paulista de Santópolis do Aguapeí, onde fiz o antigo ensino primário. A população da cidade era formada por imigrantes estrangeiros de várias nacionalidades, sobretudo japoneses, e migrantes de vários estados, além de contar com uma reserva indígena. Assim, pude ouvir durante meus primeiros onze anos, todos os dias, pessoas falando diferentes línguas estrangeiras e sotaques de diferentes regiões do país. Lembro que meus melhores amigos eram um nissei e um filho de sírio-libaneses e na casa deles eu ouvia alternadamente japonês, árabe e português. Lembro também pessoas lendo imprensa estrangeira, entre outros um jornal libanês e diferentes publicações em japonês, como o São Paulo Shimbun, que muitos habitantes assinavam. Foi em Santópolis ainda que pude seguir durante anos o cinema americano, com legendas, e, nos finais de semana, cinema japonês, também com legendas.

No antigo ginásio, que fiz nas cidades vizinhas de Tupã e Birigui, tive excelentes professores de inglês e de francês. Particularmente importante foi o acesso às bibliotecas dos colégios, onde li centenas de livros traduzidos, entre eles toda a coleção Terramarear (http://marginalia.com.br/2015/11/16/colecaoterramarear/), de livros de aventura. Um de meus irmãos era assinante do Clube do Livro, cujos volumes de literatura estrangeira eu lia com frequência.

Um acontecimento decisivo do início da adolescência foi a leitura do Suplemento Literário de $O$ Estado de S. Paulo (http://acervo.estadao.com.br/noticias/acervo,no-suplemento-literario-o-encontrode-varias-geracoes, $6862,0 . \mathrm{htm})$, jornal que meu pai assinava. No Suplemento, que eu lia de cabo a rabo toda semana, tive contato com as traduções de Augusto e Haroldo de Campos e com a coluna Letras russas, de Boris Schnaiderman, de quem eu me tornaria amigo décadas depois.

RA: Na sua formação acadêmica, quando aparece a tradução? O que mudou na área de Estudos da Tradução desde o seu primeiro contato até os dias de hoje que você considera que tenha sido importante ou marcante?

WCC: Eu tinha me interessado pela tradução a partir da leitura dos poetas concretos, feitas em suplementos, revistas e livros. O amplo leque de línguas ocidentais e orientais, modernas e antigas, do repertório concreto, me levou à tentativa de aprendizado de uma série de línguas estrangeiras, tanto em cursos de língua regulares (inglês, francês, italiano, alemão, russo, japonês) como por conta própria (espanhol, romeno). No entanto, foi durante meus estudos na KU Leuven (Katholieke Universiteit Leuven), que a prática da tradução se deu de forma cotidiana. Em primeiro lugar, ela se dava dentro de casa, pois minha esposa, na época, Sara Vergés Cabello, chilena, falava em espanhol comigo e com nossos dois filhos, Hiran e Rodrigo, e eu falava com eles em português. Quando estávamos com visitas que falavam inglês, neerlandês ou francês, falávamos 
nessas línguas com as visitas e, entre nós, em espanhol e português. Ou seja, praticávamos a tradução falada o tempo todo.

$\mathrm{Na}$ KU Leuven tive como professor José Lambert, que era um entusiasta da tradução e que estava começando a estabelecer, junto com seus parceiros belgas, da Holanda e de Israel, o que viria a ser a disciplina dos Estudos da Tradução. Eu assisti a vários eventos promovidos por Lambert e seus colegas e comecei a ler a bibliografia nascente na área. Lambert começara a orientar trabalhos sobre tradução e foi sob sua orientação que escrevi a dissertação $U n$ roman brésilien en français. Questions de traduction à propos de Grande Sertão: Veredas de J. Guimarães Rosa.

Quando entrei na UFSC, como professor da área de Espanhol, a tradução começou a fazer parte de minha prática acadêmica. A área de Espanhol passou a oferecer a tradução e a versão no ensino de língua desde os primeiros semestres e eu frequentemente ministrava essas disciplinas. Posteriormente, em uma das muitas reformas curriculares, foi introduzida a disciplina Estudos da Tradução.

Na UFSC, comecei também a desenvolver a atividade de editor, primeiro no Departamento de Metodologia de Ensino, onde eu tinha 20 horas, e, em seguida, no Departamento de Língua e Literatura estrangeiras, onde eu também tinha 20 horas. No DLLE, fui chamado pela colega Carmen Rosa CaldasCoulthard para colaborar na edição da revista Ilha do Desterro e para atuar na Pós-Graduação em Inglês, então denominada PGI. Na Ilha do Desterro, organizei o número monográfico Translation/Tradução, em 1987.1, e na PGI ministrei vários cursos sobre tradução, um deles em colaboração com Malcolm Coulthard, que viria a ser meu orientador na University of Birmingham, onde concluí o doutorado, sobre as traduções de Jorge Luis Borges para o inglês, em 1992.

RA: Você tem traduzido regularmente; como você define a sua prática?

WCC: A minha prática de tradução tem sido constante mas, ao mesmo tempo, não muito sistemática. Comecei a traduzir regularmente na Bélgica, quando, no meio do curso de Filologia Românica (Francês e Espanhol), comecei a trabalhar como jornalista na BRT (Belgische Radio en Televisie, Rádio e Televisão Belga), emissora oficial, então recém-criada para a comunidade flamenga através da divisão da antiga emissora única nacional. Durante 4 anos traduzi textos da imprensa e das agências de notícias do neerlandês para o espanhol e durante 1 ano fiz o mesmo trabalho para o português. Eu gravava esses textos que eram transmitidos pelo rádio, em onda curta, à noite.

O que eu mais traduzi, ao longo dos anos, foi poesia, em geral para revistas literárias e acadêmicas, sobretudo do espanhol, do inglês e do neerlandês. Traduzi a antologia Paisagem com uma vela e abelhas assírias, do poeta, professor e tradutor americano Steven White (Florianópolis, Edições da Orla, 1995). Também traduzi poesia (Cruz e Sousa, Leonor Scliar-Cabral) do português para o espanhol, uma experiência muito gratificante porque se tratou, nos dois casos, de uma edição multilíngue, respectivamente inglês, francês e espanhol e inglês, francês, espanhol e hebraico e que possibilitou um trabalho de interlocução com colegas como Marie-Hélène Torres e Alexis Levitin. 
Uma experiência especial foi a tradução de dois livros infantis do neerlandês para o português: Nina, do flamengo David Ausloos (Comboio de Corda, 2010) e Zoeira esteve aqui, do holandês Edward van de Vendel (SM, 2011). A relação com as editoras foi excelente e dispus da mais ampla liberdade; a revisão e a preparação de texto foram exemplares e executadas com grande delicadeza e consulta permanente.

Traduzi muito em colaboração e cabe destacar alguns desses trabalhos. Com Philippe Humblé, traduzi, em 1993, Sobre livros e leitura, de Arthur Schopenhauer, um grande sucesso da editora alternativa Paraula (com sede, primeiro em Porto Alegre e depois em Florianópolis) e que foi reproduzido na revista Buriti, da Fundação Biblioteca Nacional. Com o Philippe traduzi também alguns poemas do poeta flamengo Paul van Ostaijen. Com o saudoso Cleber Teixeira, meu grande amigo da editora Noa Noa, de Florianópolis, traduzi poemas de Octavio Paz. Com Andréia Guerini e Fabiano Seixas Fernandes traduzi Maomé - uma biografia do Profeta, de Karen Armstrong (Companhia das Letras, 2002). Com Andréia Guerini e Eclair Antônio Almeida Filho, traduzi poemas de Leopardi, publicados no Suplemento Literário de Minas Gerais. Com Rosario Lázaro Igoa, traduzi algumas crônicas de autores brasileiros para o espanhol, publicadas na imprensa uruguaia. Com Pablo Cardellino traduzi, entre outros, Cervantes e os uruguaios Felisberto Hernández e Henry Trujillo. Com Luana Ferreira de Freitas, minha esposa, traduzi o conto "A bugra", de Bram Stoker, publicado na coletânea Sombras de Carcosa-Contos de terror cósmico, da editora Poetisa, de Piracicaba. Com a Luana estou preparando atualmente uma antologia de poemas da Emily Dickinson.

RA: Você entende/assume a tradução como autoria?

WCC: A autoria na tradução costuma variar de texto para texto, de acordo com seu gênero e grau de complexidade e de tradutor para tradutor, de acordo com suas competências. Entre os exemplos citados na pergunta anterior, eu diria que o índice de autoria foi maior na tradução de poesia, na tradução dos dois livros infantis e na tradução da ficção de Felisberto Hernández e de Bram Stoker. Esse índice de autoria depende também das competências leitora e textualizadora do tradutor. Acredito que essas competências sejam translinguísticas, embora sejam aprendidas e desenvolvidas em línguas concretas. Depende também da competência retextualizadora, que acredito ser uma competência específica e que é de natureza, ao mesmo tempo, interlinguística (capacidade recriadora, de um sistema linguístico-discursivo para outro) e intralinguística (capacidade parafraseadora, dentro de um sistema linguístico-discursivo). Podemos dizer também que na tarefa do tradutor estão envolvidas três importantes competências: a competência enciclopédica e as competências lexical-idiomática e estilística.

No que se refere à tradução literária, as coisas se tornam, naturalmente, mais complexas. O índice de autoria, assim como o de relevância cultural e estética, vai depender de múltiplos fatores presentes no tempo e no lugar da produção e no tempo e no lugar da leitura. Por isso, me parece apressado dizer que as traduções têm vida mais curta que os textos-fonte. Se observarmos a história das literaturas e, dentro delas, a história das traduções, podemos dizer que 
as traduções podem apresentar, ao contrário, uma sobrevida maior, o que se deve, entre outros fatores, ao fato de que parte importante das traduções literárias é feita a partir de textos-fonte já previamente selecionados pelo público e pela crítica. É um fato que apenas uma pequena parte da produção literária mundial é traduzida e uma pequena parte dessa pequena parte é constantemente retraduzida. Só histórias da literatura traduzida, como as recentes The Oxford history of literary translation in English (Oxford: Oxford University Press, 2005, 2006, 2008, 2011) e Histoire des traductions en langue française (Paris: Verdier, 2012, 2014, 2015) podem começar a esclarecer o intrincado processo de produção e recepção das traduções literárias e sua importância para a circulação internacional de representações, temas e procedimentos, e a complexa formação do sistema mundial das literaturas e a igualmente complexa formação dos subsistemas regionais, nacionais e transnacionais.

RA: Você foi o idealizador da revista Cadernos de Tradução, hoje considerada a principal revista na área no Brasil, e na qual você figura como editor associado. Comente sobre a criação da revista e sobre como ela se insere no contexto acadêmico em relação a outras revistas.

WCC: Desde a primeira adolescência fui um grande leitor de revistas culturais, como as brasileiras Leitura, Anhembi, Brasiliense, Civilização Brasileira e as internacionais Quinzaine Littéraire, Les Temps Modernes, Critique, Strumenti Critici, Europe. Durante meu período belga (1974-1982), pude aumentar essa lista para a vasta coleção de periódicos acadêmicos da Katholieke Universiteit Leuven, tanto na biblioteca central como na biblioteca setorial de letras e linguística. Durante meu doutorado, na University of Birmingham (1988-1992), expandi ainda mais o leque dos periódicos acadêmicos lidos, especialmente os de língua inglesa.

Foi com esse quadro de leitura prévia de revistas culturais e periódicos acadêmicos que surgiu a ideia de editarmos uma revista dedicada aos Estudos da Tradução e que fosse porta-voz do recém-criado GT (Grupo de Trabalho) da UFSC, na ANPOLL, por convite da então coordenadora do GT de Tradução da ANPOLL, Maria Paula Frota, da PUC-Rio. Cadernos de Tradução começou como uma revista anual, editada pelos colegas Marie-Hélène Torres, Mauri Furlan e por mim, como órgão do também recém-criado NUT (Núcleo de Tradução) da UFSC.

Cadernos de Tradução funcionou, desde o primeiro número, publicado em 1996, segundo certos princípios: restrição da publicação de textos locais e publicação de textos nacionais e internacionais, publicação de textos em línguas estrangeiras, publicação de resenhas e inclusão de todas as correntes de pensamento da área. A revista teve um êxito imediato e, aos poucos, foi se solidificando e ganhando prestígio entre os pesquisadores do país e do exterior.

$\mathrm{O}$ grande salto aconteceu quando Andréia Guerini se tornou editora-chefe. A revista, que passou a contar regularmente com o apoio do CNPq e da CAPES, se profissionalizou e passou a sair com periodicidade regular e incorporou novas seções, como a de resenha de traduções, entrevistas e, ultimamente, traduções inéditas. Um salto importante aconteceu há pouco quando, graças a um esforço 
concentrado da editora-chefe com a então doutoranda Letícia Goellner, a Cadernos de Tradução entrou para a plataforma Scielo, o que assegura que renove automaticamente a nota A1 no Qualis da CAPES.

Cadernos de Tradução é, assim, a principal revista de Estudos da Tradução do Brasil, país onde existe o maior número de periódicos na área. $\mathrm{O}$ cenário internacional é dominado por revistas do mundo anglo-americano, o que se explica por vários motivos, entre eles, o peso de grandes grupos editoriais como Benjamins e Routledge, que controlam o rico mercado dos periódicos na principal língua franca do momento, o inglês. Até agora, as grandes editoras brasileiras não se interessaram pela edição de livros e periódicos na área dos Estudos da Tradução. Por outro lado, todos os periódicos brasileiros são ligados a instituições de ensino e são de acesso livre on-line, o que torna a pesquisa brasileira, na área, democrática e inclusiva.

RA: Você foi um dos responsáveis pela criação do primeiro programa de Estudos da Tradução no país, na Universidade Federal de Santa Catarina, e ajudou na criação de programas específicos em outras instituições, como UnB e UFC. Poderia comentar sobre esse seu movimento? Como você vê a expansão dos Estudos da Tradução no Brasil?

WCC: A criação da PGET, Pós-Graduação em Estudos da Tradução, na UFSC, se deveu a uma conjunção de fatores favoráveis, a começar pela existência de um grupo de professores apaixonado pela tradução, e que se agrupou em torno da revista Cadernos de Tradução e do NUT. Ou seja, na UFSC, o periódico especializado surgiu 7 anos antes do programa específico em Estudos da Tradução. Além de atuarem no NUT e na Cadernos, um pequeno grupo de pesquisadores já trabalhava em uma linha de pesquisa de tradução nos programas de Literatura, Inglês e Linguística. Isso explica, em parte, porque a PGET teve uma trajetória ascendente meteórica: autorizada em 2013.2, passou a funcionar em 2014.1, com uma aula inaugural emblemática, a de Boris Schnaiderman, cuja carreira inspira muito de minha atuação institucional. Na primeira avaliação da CAPES, o programa passa para a nota $4 \mathrm{e}$, em seguida, tem o doutorado autorizado com nota 5. Na Avaliação Quadrienal da CAPES do ano passado, a PGET alcança a nota 6 e não é insensato pensar que no futuro a nota 7 possa ser alcançada.

Um dos fatores que pesaram na avaliação positiva da PGET é a presença da pesquisa sobre Libras e língua de sinais . Entre as 345 teses e dissertações defendidas na PGET (https://repositorio.ufsc.br/handle/123456789/88241), entre 2004 e 2018, várias são sobre tradução e interpretação em Libras e língua de sinais.

Outro dos traços específicos da PGET é sua relação com a Bélgica, um dos países (junto com Holanda e Israel) onde nasceu a disciplina Estudos da Tradução. Eu fiz a graduação e o mestrado na KU Leuven, trajetória compartilhada por Philippe Humblé, que foi professor na UFSC durante 25 anos e hoje é professor na VUB (Vrije Universiteit Brussel, Universidade Livre de Bruxelas). Esse traço é complementado por outro, igualmente importante, a presença na PGET de docentes de origem estrangeira (mais de 20\%) e a forte 
presença de professores visitantes estrangeiros. Em certo momento, chegamos a ter 6 professores estrangeiros ao mesmo tempo, combinando as possibilidades oferecidas pela CAPES, CNPq e a própria UFSC. Entre outros visitantes que colaboraram para a face internacional da PGET, estão os ingleses John Gledson (um dos maiores especialistas em Machado de Assis e tradutor de Machado e outros escritores brasileiros) e Malcolm Coulthard (um dos expoentes da Análise do Discurso britânica e um dos fundadores da Linguística Forense), o belga José Lambert e o alemão Berthold Zilly, professor da Freie Universität Berlin (Universidade Livre de Berlim) e um dos mais importantes tradutores de literatura brasileira, na PGET há 7 anos.

Outra característica da PGET foi sua atitude não só de acolher os colegas pesquisadores de instituições nacionais e internacionais, mas também de colaborar com a formação de colegas não-doutores de instituições através do programa DINTER da CAPES. Assim, a PGET teve um DINTER com duas instituições federais da Paraíba, UFPB (Universidade Federal da Paraíba) e UFCG (Universidade Federal de Campina Grande), formando 9 doutores. Atualmente tem um DINTER com a UFPA, estando em processo de formação de 15 doutores entre os colegas docentes de diferentes campi. Nos dois casos, a coordenação coube a Marie-Hélène Torres e eu estive, e estou, bastante engajado nos dois empreendimentos.

A interdisciplinaridade típica da área dos Estudos da Tradução, que tem interface com todas as áreas de conhecimento, tem se acentuado na PGET e isso ficou claro recentemente, quando, concorrendo ao edital conjunto 01/2018/PROPG/PESQ, para integrar o Programa Institucional de Internacionalização CAPES-PrInt, a PGET apresentou um projeto, sob sua coordenação, incluindo 9 outros programas de pós-graduação da UFSC, com 32 participantes e 16 diferentes países, com 36 pesquisadores (as) estrangeiros (as). O projeto foi aprovado pela Pró-Reitoria de Pós-Graduação e aguarda implementação pela CAPES.

A PGET, através sobretudo de consultorias feitas pela Marie e por mim, tem ajudado os colegas de outras universidades que queiram montar um programa específico, ou afim, de Estudos da Tradução. Ao longo dos anos, a Marie e eu fomos consultados por colegas da UnB, UFPB, UFC, UFRJ, UFF, UFRGS e UFRN. Dessas consultas surgiram o PosTrad, da UnB, cuja fundação foi conduzida por Germana Henriques Pereira e a POET, da UFC, cuja fundação foi conduzida por Luana Ferreira de Freitas. Cabe mencionar que a Luana, que fez graduação (tradução) e mestrado (Linguística Aplicada) na UnB, fez doutorado e pós-doutorado na UFSC, na pós em Literatura e na PGET, respectivamente, e é membro permanente da PGET.

Com a POET, onde sou atualmente professor visitante, meus vínculos são especialmente fortes. Para estar com a minha esposa Luana, que tinha entrado na UFC, acabei solicitando, e obtendo, uma "colaboração técnica" na UFC entre 2013 e 2016. Assim, pude participar ativamente do processo de estabelecimento do programa e continuo participando de seu funcionamento e fortalecimento, colocando a seu serviço a experiência acumulada na UFSC. 
A parceria POET-PGET resultou em uma série de cursos e eventos comuns, tanto em Fortaleza, Florianópolis e Bruxelas, como em Bragança e Belém (no quadro do DINTER PGET/UFPA) como em colóquios nacionais da ABRALIC e da ANPOLL. Essa parceria também se estende à participação em associações (ABRAPT, GT de Tradução da ANPOLL), participação de professores da PGET como professores na POET (atualmente Marie-Hélène Torres e Silvana dos Santos Aguiar), na publicação conjunta de livros e participação intensa em bancas dos dois programas e coorientação de dissertações e teses.

Em termos de expansão da área, os Estudos da Tradução têm experimentado uma verdadeira explosão no Brasil. Assim, o Diretor do Departamento Luso-Brasileiro do Instituto de Tradução e Interpretação da Universidade de Heidelberg, Alemanha, Thomas Sträter, observou, em sua palestra proferida na POET/UFC, em 03/05/18, intitulada "Por que (Estudos da) Tradução?”, que o Brasil é o país onde mais se pesquisa sobre tradução. exterior?

RA: Como você vê a institucionalização dos Estudos da Tradução no

WCC: Apesar do êxito da disciplina entre os pesquisadores e na indústria editorial, sobretudo de língua inglesa, a institucionalização dos Estudos da Tradução no exterior me parece problemática. Curiosamente, o único país onde a disciplina possui programas específicos fortes, e com grande número de mestrandos, doutorandos e pós-doutorandos, é o Brasil. $\mathrm{Na}$ maior parte dos países, o que predomina são programas de treinamento de tradutores e intérpretes, não de Estudos da Tradução em nível de mestrado e doutorado. O Reino Unido se destaca por apresentar um grande número de mestrados e doutorados, mas isso se deve à flexibilidade da universidade britânica, que permite que se ofereça pósgraduação stricto sensu em uma determinada área com um número reduzido de professores.

Cabe lembrar igualmente outros países em que os Estudos da Tradução possuem uma inserção institucional, a começar por dois países tradicionalmente fortes: Bélgica, mais precisamente em Flandres, onde as antigas escolas de interpretação foram absorvidas pela KU Leuven, Universiteit Antwerpen e VUB; e Canadá, onde a disciplina está bem estabelecida em várias universidades e onde são editadas algumas das mais importantes revistas internacionais como Meta e TTR. Na Espanha (com destaque para Barcelona) e em Portugal, os Estudos da Tradução alcançaram uma posição institucional importante. Um fenômeno novo é que os colegas portugueses têm preferido publicar, e realizar muitos eventos, em inglês.

Mais países se sobressaem: Turquia, África do Sul, Índia, Austrália e Malásia. A China é a grande novidade e parece haver abraçado a causa dos Estudos da Tradução, potenciando uma tradição que já existia em Hong Kong e Macau. Nas publicações internacionais em inglês, tanto em periódicos como em livros, a presença de autores chineses se tornou uma constante.

Aqui, devemos o atual reconhecimento dos Estudos da Tradução, em grande parte, à colega Sandra Regina Goulart Almeida, atual reitora da UFMG. A 
Sandra foi, antes de se candidatar a vice-reitora da UFMG, vice-coordenadora da área de Letras e Linguística da CAPES. Nesse cargo, ela, em consonância com o coordenador, Dermeval da Hora, defendeu e promoveu os Estudos da Tradução. Em consequência, durante os 7 anos de mandato do Dermeval, os Estudos da Tradução foram reconhecidos pela CAPES e alguns de seus representantes, como Andréia Guerini e eu, fomos sistematicamente convidados a participar da comissão de avaliação dos programas, assim como de outras instâncias, como o Prêmio CAPES de Tese. Na gestão do Dermeval, houve ganhos importantes para a área como o reconhecimento de tradução de artigo como artigo e tradução de livro como livro.

RA: A bibliografia sobre Estudos da Tradução vem aumentando exponencialmente desde a criação da disciplina na década de 70/80 do século $X X$. Como você avalia esse incremento?

WCC: A bibliografia vem aumentando muito nos últimos anos, superando outras disciplinas consagradas. No entanto, como costuma acontecer, esse crescimento é desigual, tanto em termos de línguas e países, como de subáreas. Assim, nas últimas décadas, temos visto aumentar o número de publicações, sobretudo em inglês, e especialmente em áreas antes pouco exploradas, como interpretação (que se tornou, praticamente, uma área independente), tradução audiovisual, interpretação e tradução em língua de sinais. Por outro lado, setores que existiam antes da disciplina, como os estudos da tradução literária, têm crescido pouco no cenário internacional. No Brasil, os Estudos da Tradução literária continuam uma área forte e constituem parte significativa da produção nacional.

Há também o fenômeno recente da publicação digital, em que o Brasil se destaca, já que todos os trabalhos das universidades públicas, como TCCs (Trabalhos de Conclusão de Curso, da graduação), dissertações e teses, estão disponíveis on-line. É uma produção enorme e valiosa, pouco conhecida e pouco estudada, e cada vez mais utilizada.

Seria importante que a bibliografia fosse mais conhecida, com a publicação, em livre acesso, de bibliografias críticas, que descrevessem e avaliassem esse riquíssimo material.

RA: $O$ que ainda precisa ser feito para que a área de Estudos da Tradução avance e ganhe mais visibilidade no país e no exterior?

WCC: A área está bem estabelecida em termos de publicação, com as limitações assinaladas acima, mas não em termos de institucionalização, que é o que garante mais visibilidade e um desenvolvimento sustentado por dar acesso a fontes de financiamento estáveis. Acredito que se trata mais de um problema político-institucional do que propriamente acadêmico. Uma iniciativa que julgo essencial é aumentar o diálogo com outras disciplinas, o que quer dizer aumentar o diálogo com todas as disciplinas. Outra iniciativa importante é que a pesquisa em Estudos da Tradução seja mundial, quer dizer, que abarque todos os continentes, línguas e culturas, e que seja multilíngue.

Cabe considerar que houve retrocessos também. Na Alemanha, país pioneiro e relevante em vários momentos históricos no estudo da tradução, os 
Estudos da Tradução parecem enfrentar dificuldades institucionais. O mesmo ocorre na França e, mais ainda, nos Estados Unidos.

RA: Como você vê a percepção do papel e da importância da tradução fora da academia? Essa percepção mudou? Em que sentido?

WCC: Mudou em alguns setores; ainda resta muito por mudar. Há prêmios para as traduções, sobretudo literárias; há editais da Fundação Biblioteca Nacional com bolsas para tradutores de obras literárias brasileiras para outras línguas. As grandes editoras estão mais sensíveis: costumam colocar o nome do tradutor na folha de rosto e, em alguns casos, na capa; instruem os revisores e os preparadores de texto para terem uma atitude tolerante com as opções dos tradutores; privilegiam as traduções diretas, sempre que possível. Por outro lado, alguns maus costumes permanecem: nos sites das livrarias, os tradutores quase nunca são mencionados e o mesmo acontece em boa parte dos TCCs, dissertações e teses em estudos da tradução... Os direitos autorais dos tradutores são ainda muito limitados, com exceção de países como a Holanda.

Em termos internacionais, a situação não é muito diferente, embora haja prêmios, sobretudo de traduções literárias. Um desenvolvimento importante é o das casas de tradutores, que começam a se espalhar por vários países, inclusive no Brasil, a partir de uma iniciativa de colegas da UFF e da Fundação Biblioteca Nacional, que encampou a ideia, em que a PGET tem participado ativamente. academia?

RA: Ainda pensando na pergunta anterior, como se dá dentro da

WCC: Estamos longe do reconhecimento da importância da tradução e dos Estudos da Tradução. Mesmo em Letras, onde ela é mais reconhecida, e onde boa parte da bibliografia é constituída de obras traduzidas, há certo preconceito contra o texto traduzido como objeto de pesquisa.

Acredito que a existência de programas de pós-graduação stricto sensu bem qualificados pode ajudar nesse processo, que é, necessariamente longo. O reconhecimento das agências de fomento é igualmente importante e, no Brasil, a situação é muito mais favorável que em outros países. No entanto, apesar do avanço, os Estudos da Tradução ainda não constam como subárea no CNPq e na CAPES.

RA: Como você vê o futuro da tradução e o seu estudo num mundo cada vez mais conectado?

WCC: Acho que o futuro da tradução e dos Estudos da Tradução será riquíssimo. Por uma feliz conjunção de fatores, em que a internet ocupa o lugar central, a tradução agora está ao alcance de todas as pessoas do planeta, que dominem algum sistema linguístico, de forma "gratuita" (de fato, paga por anúncios). A face mais visível disso são os tradutores automáticos que, no momento alcançaram tal nível de sofisticação, que qualquer pesquisador pode ler qualquer texto, escrito em centenas de línguas de todos os continentes, de forma rápida e bastante eficiente, sobretudo se esse pesquisador dominar o inglês e mais algumas línguas. Os eventuais problemas podem ser corrigidos através de uma grande quantidade de dicionários on-line, também financiados por anúncios, a maior parte dos quais apresenta uma interface de tradução, como os dicionários 
Oxford, Cambridge e Larousse, e centenas de outros. Outro instrumento para a a progressiva sofisticação das traduções automáticas são as concordâncias on-line, cada vez mais numerosas e maiores, abarcando um grande número de línguas.

Posso mostrar isso, com um exemplo, da área dos Estudos da Tradução. Durante muito tempo, eu me interessei por Jiř́ Levý (1926-1967), de quem ouvi falar pela primeira vez em Leuven, em um curso ministrado por José Lambert. Ontem, em Florianópolis, e hoje, em Fortaleza, Lambert mantém a mesma admiração pelo colega tcheco, falecido tão precocemente. Levý, que possui uma obra gigantesca para os poucos anos que viveu, tem uma contribuição significativa não só para os Estudos da Tradução, mas para os Estudos Literários como um todo e, mais especificamente, para o estudo da poesia e do verso.

Pois bem, graças aos tradutores automáticos, aos diferentes dicionários e concordâncias, e também ao conhecimento de algumas línguas estrangeiras, agora posso ter acesso direto ao texto tcheco.

Como experimento, procurei e achei a edição tcheca de sua obra mais conhecida, Uméní překladu, de 1963, que teve uma primeira tradução alemã, Die literarische Übersetzung - Theorie einer Kunstgattung, em 1963 e uma tradução para o inglês apenas em 2011.

Reproduzo, abaixo o primeiro parágrafo do texto tcheco, seguido de sua tradução pelo Tradutor do Google e pelo tradutor Patrick Corness.

\begin{tabular}{|l|l|l|}
\hline & $\begin{array}{l}\text { Tradução do Google } \\
\text { Tradutor para o inglês } \\
\text { em 09/04/18 }\end{array}$ & $\begin{array}{l}\text { Levý, Jiř́í. The art of } \\
\text { translation. Translated } \\
\text { by Patrick Corness. } \\
\text { Edited with a critical } \\
\text { foreword by Zuzana } \\
\text { Jettmarová. } \\
\text { Amsterdam/Philadelphia: } \\
\text { Benjamins, 2011, p. 3. }\end{array}$ \\
\hline $\begin{array}{l}\text { Literatura o překládání se jen } \\
\text { zčásti pohybuje v rovině } \\
\text { teoretické, do dnešního dne } \\
\text { většina studií i knižních } \\
\text { publikací nepřesahuje hranice } \\
\text { empirických pozorování nebo } \\
\text { esejistických aforismů. }\end{array}$ & $\begin{array}{l}\text { Literature on translating } \\
\text { is only partly in the } \\
\text { theoretical plane; to date, } \\
\text { most studies and books } \\
\text { publications does not go } \\
\text { beyond boundaries of } \\
\text { empirical observations or } \\
\text { eseistic aphorisms. }\end{array}$ & $\begin{array}{l}\text { To date, writing on } \\
\text { translation only partially } \\
\text { belongs to the realm of } \\
\text { theory, as most articles } \\
\text { and monographs have } \\
\text { been confined to } \\
\text { empirical observation or } \\
\text { essayistic aphorisms. }\end{array}$ \\
\hline
\end{tabular}

Assinalei em amarelo alguns probleminhas da tradução do Google. Comparada com as primeiras traduções automáticas, esta tradução me parece próxima do tipo de tradução que necessito para conhecer a obra de Jiř́ Levý, a partir do texto tcheco e me valendo, claro, do conhecimento de outras línguas estrangeiras (inclusive um pouco de russo) e do conhecimento da área dos Estudos da Tradução. 
Estou curioso por estender esse primeiro experimento para os outros trabalhos de Estudos da Tradução de Levý, como České teorie překladu [Teorias tchecas da tradução], de 1957, e para os seus inúmeros textos sobre versificação.

Andreia Guerini

Andreia.Guerini@gmail.com

Robert de Brose

$\underline{\text { Robert.de.Brose@gmail.com }}$

Recebido em: 6/9/2017

Aceito em: 2/2/2018

Publicado em Abril de 2018 